\title{
Analysis Of Employment And Job Profiles Of Renewable Energy: The Case Of The European Union
}

María Teresa García-Álvarez, University of Coruna, Spain Rosa María Mariz-Pérez, University of Coruna, Spain

\begin{abstract}
In recent years, the European Union (EU) is involved in a process of intense development of renewable energy. One of the basic aims is to reduce atmospheric pollution. However, this type of production technologies also entails important social-economic implications including employment creation. The objective of this paper is to analyze the creation of employment due to the development of the main clean production technologies in the EU. In addition, we will study the main characteristics of the necessary job profiles in this new industry where their main skills and educational background will be analyzed.
\end{abstract}

Keywords: Renewable Energy Development in the EU; Clean Energy Employment and Job Profiles

\section{INTRODUCTION}

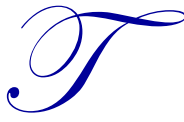

he Kyoto Protocol establishes the reduction of greenhouse gas emissions, responsible for the global warming. In this context, the EU is involved in the commitment of reducing these emissions in $8 \%$ during the time period from 2008-2012 and in 20\% in 2020.

This means that the public promotion of renewable energies emerges as a political priority of the within the EU and much regulation and legislation on this subject has become in force. In this context, Directive 2009/28/CE establishes three obligatory objectives for all member states in 2020: a) reduction in the greenhouse gas emissions in a share of $20 \%$, b) a lowering of primary energy consumption in a share of $20 \%$ by increasing energetic efficiency and c) the obtaining of a global quota of $20 \%$ of renewable energy in final energetic gross consumption.

Therefore, the objective is not only to reduce the greenhouse gas emissions but to obtain other advantages from such production technologies (for example, the reduction of the foreign energy dependency or its contribution to employment).

In this context, the participation of governments is necessary in the initial phase in order to ensure the development of renewable energies and protecting them from direct competition of conventional technologies. This governmental support can be justified in three manners: the correction of the negative externalities derived from the use of fossil combustible, the stimulation of technical change and the promotion of innovation (Jordan-Korte, 2011; Menteneau et al., 2003).

However, European legislation does not establish a certain renewable energy promotion mechanism in for all member states, but it gives freedom for each country to choose the specific support instrument. There are two main categories: regulatory price-driven and regulatory quantity driven mechanisms (Hass et al., 2011).

Regulatory price-driven mechanisms include feed-in tariff. This system entails an obligation for the grid operator to buy all renewable electricity produced through pricing scheme where producers have two options: a) they can sell their renewable electricity production at a pre-set fixed price per kilowatt-hour (feed-in tariff), usually higher than 
conventional market price for electricity or b) producers can sell renewable electricity at market price plus a premium. In both cases, the value established by tariffs is guaranteed to be added to the price for a number of years (Venetis et al., 2009). This type of incentive is the older and widely used in countries such as Spain, Denmark, Germany and Italy.

Regulatory quantity driven mechanisms include tradable certificate systems. This mechanism is characterized by the fact that producers of renewable electricity receive a certificate for each pre-defined unit of electricity they produced. These certificates represent the "social value" of the production of electricity from renewable energies and it is tradable and sellable through a competitive trading system. This mechanism is being used, or recently will be use, in various countries on a more or less experimental basis (Netherlands, Denmark, Sweden or Italy).

These systems have participated in creation of different types of employment -direct, indirect and induced-. Research results in this topic show that renewable energy entail more job creation than the use of fossil combustibles (European Wind Energy Association and Greenpeace, 2009; SkyFuels and National Renewable Energy Laboratory, 2009; EPIA and Greenpeace, 2006).

The objective of our paper is to analyze the implications of renewable energies (with respect to their production technology) of the EU on employment. Besides, we will also analyze the main skills and educational background required in the job profiles of this industry in expansion. For this purpose, the paper is structured in the following way: firstly, we analyze the policies of renewable energy in the EU. After that, we study the implications of renewable energy on employment. Later, we analyze the required characteristics of the job profiles in this industry and, finally, we extract the main conclusions of the paper.

\section{RENEWABLE ENERGY POLICIES IN EU: CHARACTERISTICS AND EVOLUTION}

The beginning of the support policy and strategy for renewable energies, in the EU, is developed with the presentation of the White Paper for a Community Strategy and Action Plan in 1997. Its main objective is to change the European energetic model to reduce the contaminant emissions of carbon dioxide and to achieve the objectives established in the Kyoto Protocol. With this aim, the Paper establishes an objective of $12 \%$ in 2010 for energetic consumption from renewable energy in the EU.

Due to the recommendations of the White Paper, Directive 2001/77/CE on the promotion of electricity produced from renewable energy sources in the internal electricity market comes into force. This regulation establishes, as an indicative objective, a share of renewable energies on energetic consumption of $21 \%$ in the EU in 2010. For this, legislation determines the indicative -not obligatory- objectives for every country with respect to its renewable potential and its initial situation. However, this Directive does not fix a common promotion system for renewable energy in all member states and each country will decide which mechanism is the most suitable according to its specific characteristics (energetic consumption, energetic diversity or composition of the electricity generation).

Later, Directive 2009/28/CE establishes the obligation of achieving a 20\% share of renewable energies in energetic consumption in 2020. It indicates a common project for EU countries, with a prearranged timetable and clear objectives. The aim is to introduce, definitely, a clean technology which requires institutional support. However, this regulation allows each member to choose its own mechanism for renewable promotion.

The diversity of the renewable support mechanisms (based on prices and quantity) applied by member states has entailed different levels of development of these production technologies. However, there is non unanimity about what policy is most suitable for promoting clean energy (Hass et al., 2011; Jacobson et al., 2009; Dinica, 2006; Meyer, 2003). A key concept, in both policy types, is the development of regulatory stability which guarantees adequate profitability and reduces risk for investors.

This legislation has achieved a $15.60 \%$ share of renewable energies in production capacity in EU-27 (see Graph 1) where hydraulic technology has a key role, followed by wind and biomass (see Graph 2). 
Graph 1. Gross electricity production-EU 27. 2008

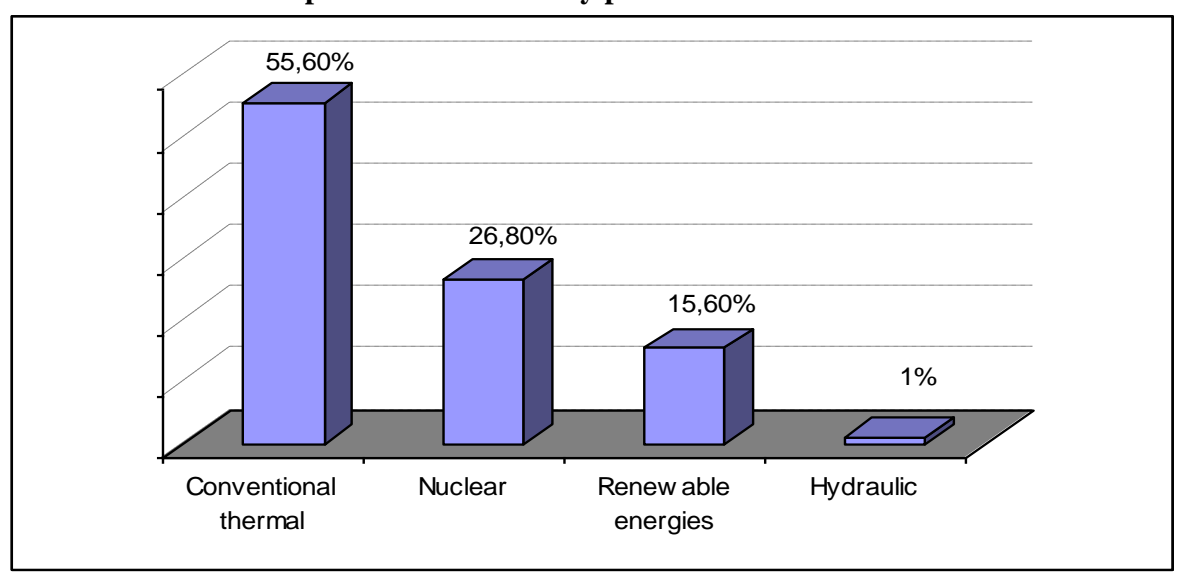

Source: European Commission (2010)

Graph 2. Gross electricity production from renewable energies-EU 27

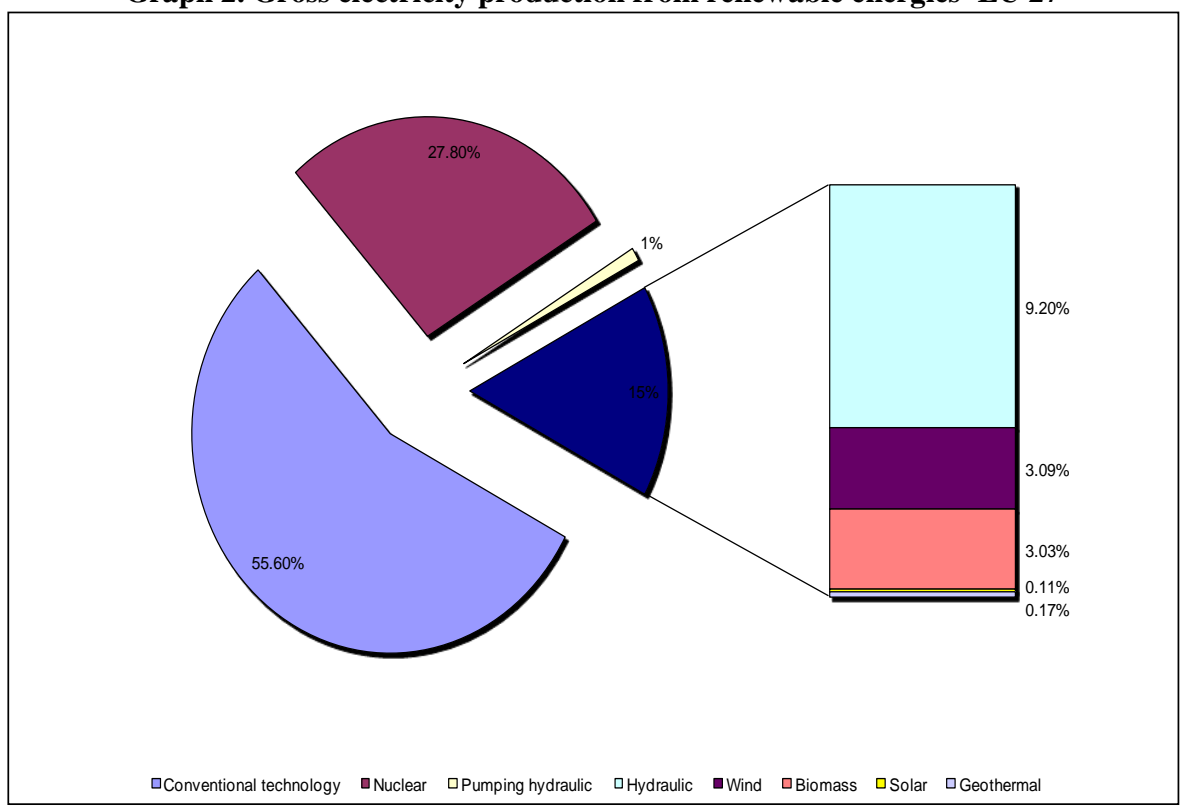

Source: European Commission (2010)

ANALYSIS OF THE IMPLICATIONS OF RENEWABLE ENERGY ON EMPLOYMENT: THE CASE OF THE EU

\section{Wind energy}

Wind energy is a rather mature technology in the European Union; this entails benefits related to scale economies and increased efficiency. So, Europe is the world leader in installed capacity, manufacture and investment and in research activities related to this production technology.

Graph 3 shows the evolution of installed wind capacity in the main member states. We can observe that Germany and Spain are the European leader countries in this renewable production technology. Installed capacity has supposed more than $35 \mathrm{Gwh}$ in 2010 in both member states. 
The wind energy promotion mechanism of Germany and Spain is based on feed-in tariffs. Therefore, this renewable production technology, in these member states, is based on a fixed price or in the wholesale electricity price plus an incentive that compensates the environmental value of the renewable production.

Graph 3. Evolution of installed wind capacity in EU

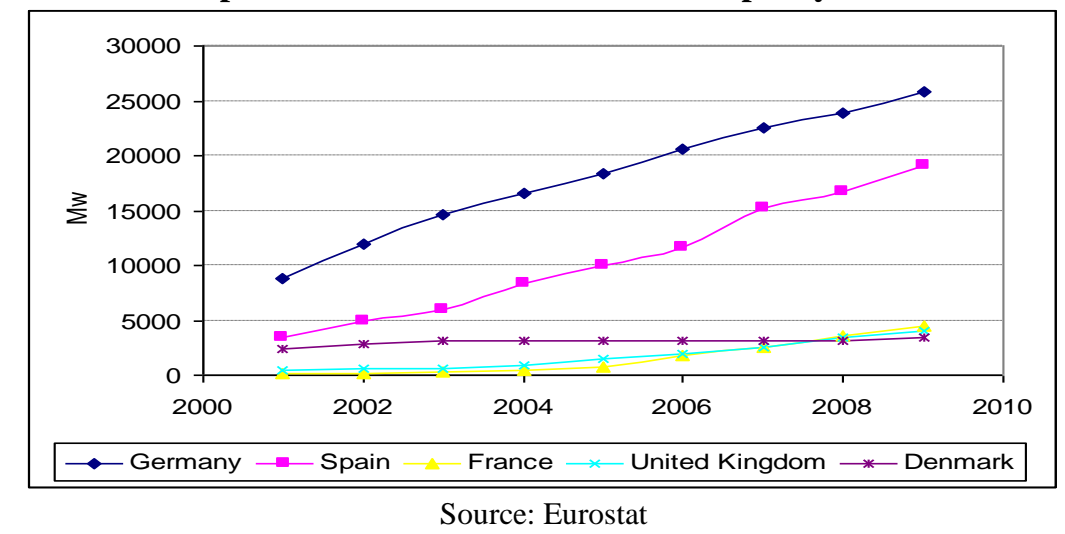

In Graph 4, we can see the level of employment that wind energy has generated in 2009. Germany has a share of $53 \%$ of the jobs from this production technology and, behind, Spain holds a quota of $25 \%$. After these countries, we can observe the cases of Denmark (15\%), France (4\%) and United Kingdom (3\%).

Graph 4. European employment in wind energy. 2009

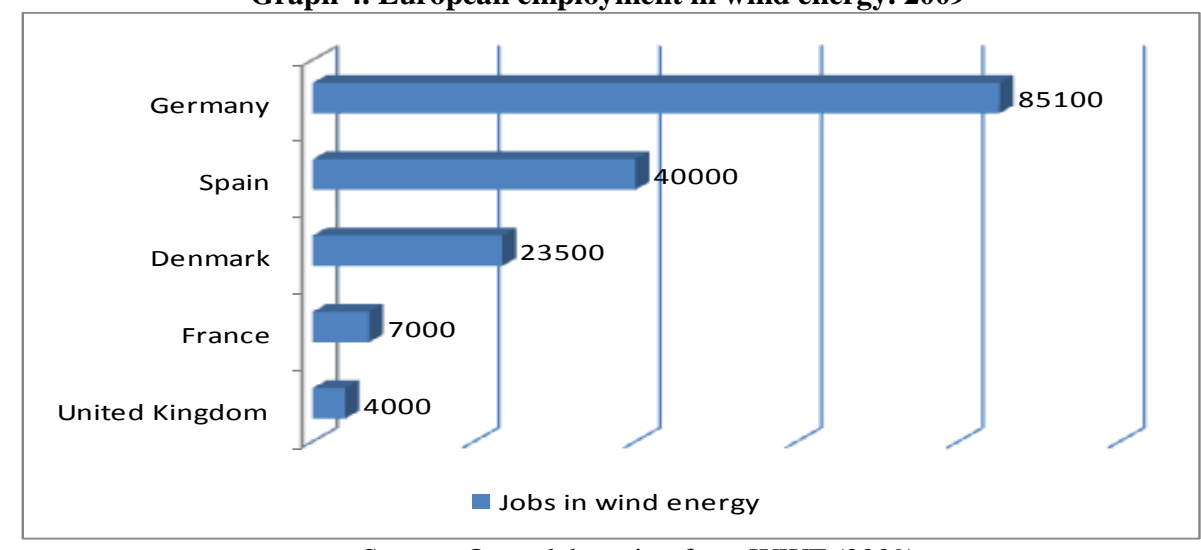

Source: Own elaboration from WWF (2009)

\section{Photovoltaic and thermal solar}

Photovoltaic and thermal solar are renewable production technologies in expansion. They allow the direct conversion of solar radiation into electricity energy. In the first case, photovoltaic systems allow to supply energy demand in the grid from remote power supplies. With regard to thermal solar, energy is produced by installations (thermal collectors) which collect (and in some designs concentrate) solar radiation and transfer the energy to a working fluid, raising its temperature (European Commission, 2006).

In Graph 5 and Graph 6, we can observe the evolution of installed photovoltaic and thermal solar capacity in the main member states. Again, we can observe that Germany and Spain are the European leader countries in these renewable production technologies. The promotion mechanism employed, in these cases, is again based on feed-in tariffs. 
Graph 5. Evolution of installed photovoltaic solar capacity in EU

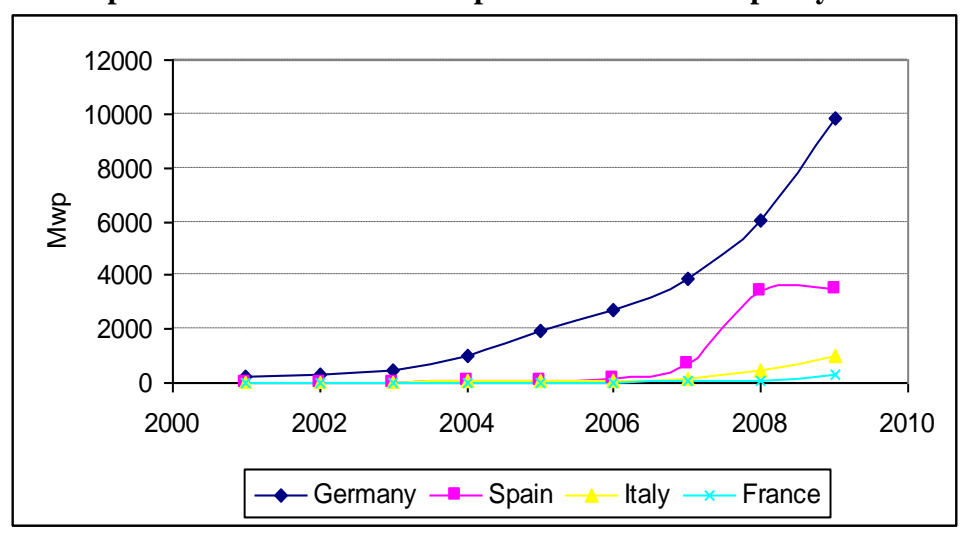

Source: Eurostat

Graph 6. Evolution of installed thermal solar capacity in EU

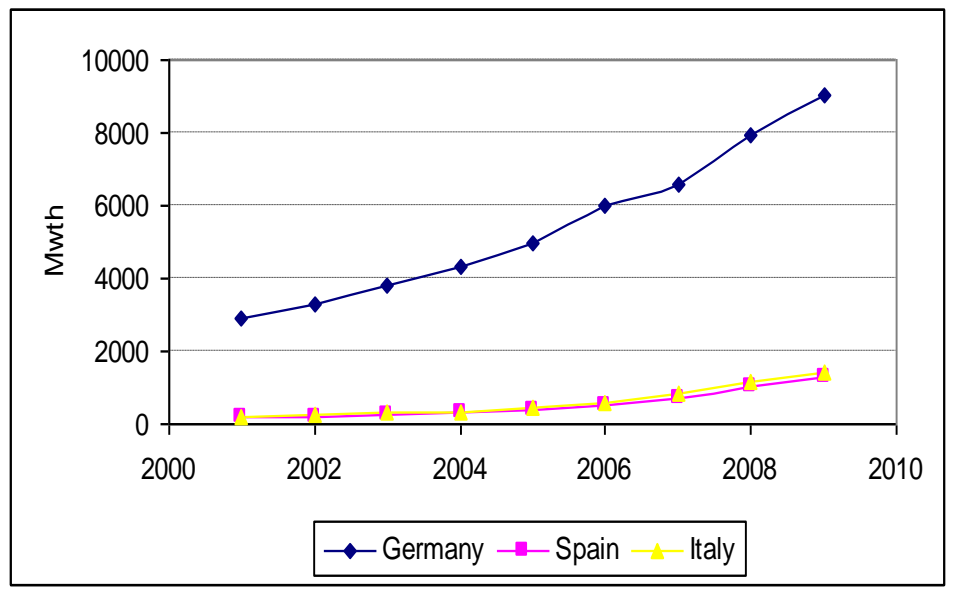

Source: Eurostat

With regard to employment, in the case of photovoltaic and thermal solar energy (see Graph 7 and Graph 8), Germany (with a quota of around $50 \%$ in both cases) and Spain (with a share slightly greater than $30 \%$ in both cases) have the first positions again.

Graph 7. European employment in photovoltaic solar energy. 2009

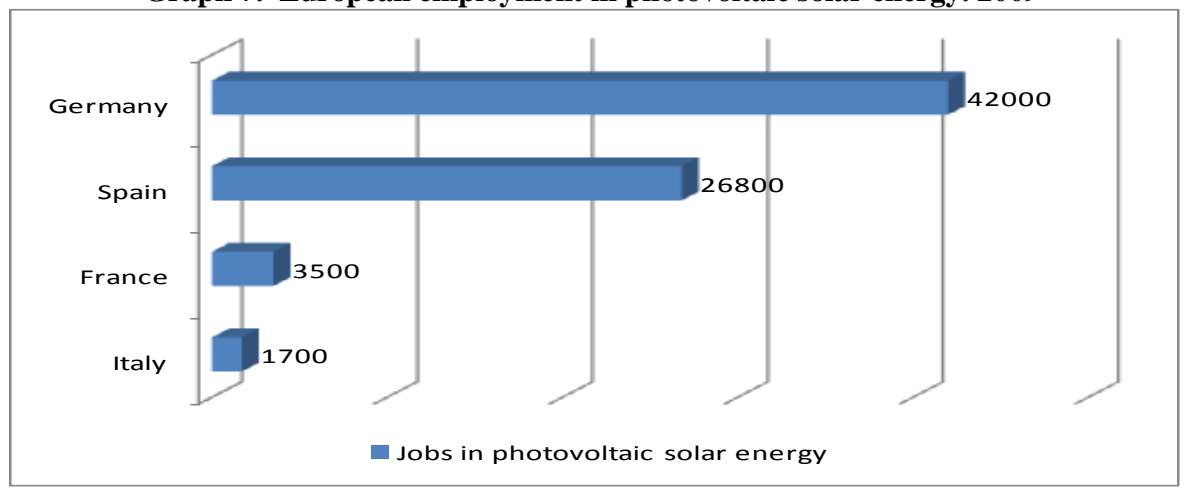

Source: Own elaboration from WWF (2009) 
Graph 8. European employment in thermal solar energy. 2009

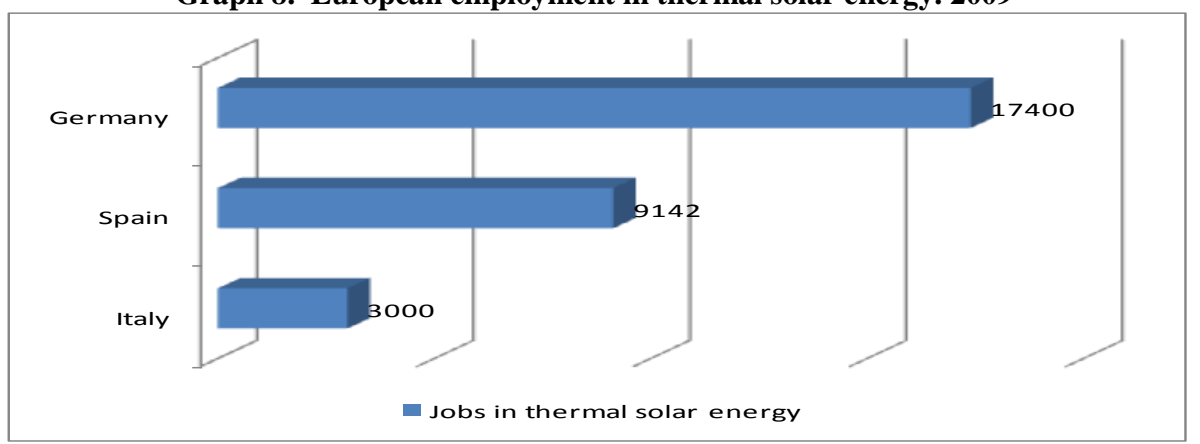

Source: Own elaboration from WWF (2009)

\section{ANALYSIS OF JOB PROFILES IN EUROPEAN RENEWABLE ENERGIES.}

Employment in renewables is characterized by presenting differential aspects of those related with the traditional extractive industries. So, a main challenge in this industry in expansion is given by the availability of trained employees in order to continue with the development of the industry.

In Table 1, we can observe the main job profiles with respect to the renewable production technology.

Table 1. Job profiles in renewable energy industry

\begin{tabular}{|c|c|c|c|}
\hline \multirow[b]{2}{*}{ Occupation } & \multicolumn{3}{|c|}{ Renewable energy industry } \\
\hline & Photovoltaic solar & Wind power & Thermal solai \\
\hline Administrative manager & $\mathrm{X}$ & $\mathrm{X}$ & $\mathrm{X}$ \\
\hline Architect & $\bar{X}$ & & $\bar{X}$ \\
\hline Chemical Engineer & $\bar{X}$ & & \\
\hline Civil Engineer & $x$ & $\mathrm{X}$ & \\
\hline Electrical Engineer & $\bar{X}$ & $\mathrm{X}$ & $\mathrm{X}$ \\
\hline Environmental Engineer & $\bar{X}$ & $\mathrm{X}$ & $\bar{X}$ \\
\hline Lawyer & $\mathrm{X}$ & $\mathrm{X}$ & $\mathrm{X}$ \\
\hline Manufacturing Engineer & $\bar{X}$ & $\mathrm{X}$ & $\bar{X}$ \\
\hline Marketing Executive & $\bar{X}$ & $\mathrm{X}$ & $\bar{X}$ \\
\hline Material Scientist & $\bar{X}$ & $\mathrm{X}$ & $\mathrm{X}$ \\
\hline Mechanical Engineer & $\bar{X}$ & $\bar{X}$ & $\bar{X}$ \\
\hline Meteorologist & $\mathrm{X}$ & $\mathrm{X}$ & \\
\hline Micrositing Engineer & & $\mathrm{X}$ & \\
\hline Planning Consultant & $\mathrm{X}$ & $\mathrm{X}$ & \\
\hline Project Manager & $\mathrm{X}$ & $\mathrm{X}$ & \\
\hline Public Relations Officer & & $\mathrm{X}$ & \\
\hline Renewable Energy Installations Assesor & $\bar{X}$ & $\mathrm{X}$ & \\
\hline Research Engineer & $\mathrm{X}$ & $\mathrm{X}$ & \\
\hline Sales Technician & $\mathrm{X}$ & $\mathrm{X}$ & \\
\hline Technician in Renewable Energy applied to Buildings & $\bar{X}$ & $\mathrm{X}$ & \\
\hline Technician in Renewable Energy applied to Industry & $\mathrm{X}$ & $\mathrm{X}$ & \\
\hline
\end{tabular}

Source: European Commission (2006)

We can distinguish three types of employment: a) technical jobs, b) jobs based on management; b) jobs based on customers.

With regard to technical employment (such as the different types of engineers or the technicians in buildings and industry), employees will tend to collaborate in multidisciplinary teams of designers, engineers and technicians. Therefore, it is necessary for them to possess communicative, work-group and information technologies skills. Besides, an educational background is required (with the required degree - engineer, architect, technician- and positive assessment of master and Ph.D.). 
In the case of jobs based on management (such as administrative manager, planning consultant or project manager), employees undertake tasks that are not directly related to the core activities. They will tend to coordinate the different resources of the enterprise with the aim of obtaining the established objectives. These employees should have organizational and resource management, interpersonal and communication and information technologies skills. Again, an educational background is necessary (with the degree level of the related areas).

Finally, with regard to employment based on customers, they have to stimulate interest through the development of new products in the enterprise, the powering of a suitable brand image and the establishment of good relationships with the clients in all time periods. Given that renewable energy is an emerging industry, it is especially relevant to establish this contact with customers in order to transmit the technical characteristics of the products. The main skills of this type of employees should be given by good interpersonal, communication and presentation, organizational skills and, at least, a basic technical knowledge. They should have to a suitable educational background based on the marketing field.

The main challenge of this industry is that there is not a specific degree in renewable energies (although it could be postgraduate and specialization courses). Hence, the importance of establishing the required educational background and the adequate employee skills is crucial to reach suitable competitiveness in this industry.

\section{CONCLUSIONS}

Over the last years the EU is living a process of intense development of renewable energy. Two of the basic aims are to reduce atmospheric pollution and to achieve sustainability with regard to fossil sources.

With the aim of accomplishing these benefits, the participation of governments is necessary in the initial phase of the promotion of renewable energy in order to secure development and protection from direct competition engaged by conventional technologies. In this context, there are two main types of renewable promotion systems: mechanisms based on price or on quantity.

These characteristics have allowed that renewable energy entail, nowadays, a quota of around $15 \%$ of gross electricity production in EU. The cases of wind and solar production technologies can be highlighted. Besides, it also entails implications in very relevant variables to the economy, such as the case of employment.

Employment generated by these technologies in EU can be valued at around 400,000 jobs in the EU. The great effect of renewable energy on employment is observed in Germany and Spain, this is, the European leader countries with regard to installed power in these production technologies. The development of renewable energy in these member states has been driven by support systems based on feed-in tariffs.

Finally, it is necessary to detect the main competences and qualifications that are necessary in this industry in expansion give its differential characteristics. We have distinguished three types of employment a) technical jobs, b) jobs based on management; b) jobs based on customers. It is especially relevant to detect the required skills and educational background due to the non existence of a specialized degree in renewable energy.

\section{ACKNOWLEDGEMENT}

This paper has been developed in the framework of the 10SEC100020PR Project "Analysis of the effects of renewable energies on employment in European Union" supported by the Xunta of Galicia.

\section{AUTHOR INFORMATION}

María Teresa García-Álvarez, University of Coruna, Faculty of Economy, Department of Economic Analysis and Business, Campus Elvina s/n, 15070 A Coruna, Spain. E-mail: mtgarcia@udc.es. Corresponding author.

Rosa María Mariz-Pérez, University of Coruna, Faculty of Economy, Department of Economic Analysis and Business, Campus Elvina s/n, 15070 A Coruna, Spain. E-mail: rmariz@udc.es 


\section{REFERENCES}

1. Dinica, V. (2006). Support systems for the diffusion of renewable energy technologies - an investor perspective. Energy Policy, Vol. 34, No. 4, pp. 461-480.

2. European Commission (2009). Directive 2009/28/EC of the European Parliament and of the Council of 23 April 2009 on the promotion of the use of energy from renewable sources and amending and subsequently repealing Directives 2001/77/EC and 2003/30/EC.

3. European Commission (2007). White Paper for a Community Strategy and Action Plan. Energy for the future: renewable energy sources of Energy. COOM (97) 599 final.

4. European Commission (2006). Employment in the renewable energy sector. Handbook for career advisors and occupational councillors. Community Action programme on vocational training. Agreement $\mathrm{n}^{\mathrm{o}}$ $\mathrm{EL} / 2004 / \mathrm{B} / \mathrm{F} / \mathrm{PP} / 148-259$.

5. European Commission (2001). Directive 2001/77/CE of the European Parliament and the Council of 27 September 2001 on the promotion of electricity produced from renewable energy sources in the internal electricity market.

6. European Photovoltaic Industry Association (EPIA) and Greenpeace (2006). Solar generation: solar electricity for over one billion people and two million jobs for 2020.

7. European Wind Association and Greenpeace (2009). Wind at work: wind energy and job creation in the EU.

8. Haas, R., Panzer, C., Resch, G., Ragwitz, M., Reece, G. and Held, A. (2011). A historical review of promotion strategies for electricity from renewable energy sources in EU countries. Renewable and Sustainable Energy Reviews, Vol. 15, pp. 1003-1034

9. Jacobson, S., Bergek, A., Finon, A., Lauber, V., Mitchell, C., Toke, D., and Verbruggen, A. (2009). EU renewable energy support policy: faiths or facts? Energy Policy, Vol. 6, pp. 2143-2146.

10. Jordaan-Korte, K. (2011). Government promotion of renewable energies technologies. Gabler verlag: Berlin.

11. Mentaneau, P., Finon, F., and Lamy, M.L. (2003). Prices versus quantities: choosing policies for promoting the development of renewable energy. Energy Policy, 31, 799-812.

12. Meyer, N.I. (2003). European schemes for promoting renewables in liberalized markets. Energy Policy, Vol. 31, No. 7, pp. 665-676.

13. Skyfuels and National renewable Energy Laboratory (2009). Solar thermal jobs data. Personal communication, 21 March.

14. United Nations Framework Convention on Climate Change (2007). Kyoto Protocol. Japan.

15. Venetis, I.A. (2009): Financial mechanisms and regulatory recommendations for technologies based on biogas from waste/deliverable (D5.1.). Biores-EIE/07/045/SI2.466790. Intelligent Energy, Europe.

16. WWF (2009). Low carbon jobs for Europe. Current opportunities and future prospects. 